\title{
Aircraft seat: the study of airline seat pitching and comfortable
}

\author{
Kangwarn Phothong ${ }^{1, *}$ and Benjapol Worasuwannarak ${ }^{1}$ \\ ${ }^{1}$ College of Hospitality Industry Management, Suan Sunandha Rajabhat University, Thailand
}

\begin{abstract}
Legroom is the most critical of the aircraft economy category that affects passenger comfort. Legroom is the most significant improvement in passenger comfort, particularly in today's Low-Cost carrier, by reducing the legroom to 29 inches on average, whereas the usual seat pitch of the full-service airline is 31 inches. The capacity to change the seat pitch is in the range of 28 to 43 inches within the airline interior mock up. A study to investigate the function of seat pitches that affect passenger well-being during en-route flights. In the main analysis, the understanding of the various seat pitch settings and the ability to relocate seating postures for passengers during short-haul and long-haul flights are shown. In addition, during flight time, the research aims at the emotion of the passenger in the seat duration. As a result of this study, it demonstrates the role between the airline's seating concept and seat pitch anthropometry that can be established and enhance the passenger posture feature while seating on the limited seat. In addition, the technique of seating in the minimal of seat pitches for passengers to become the flight comfort well.
\end{abstract}

\section{Introduction}

Passenger picks the airline to fly by destination, convenience, and price. Most people would put the word "loyalty" to the list of airline comfortable criteria, including on how reasonable airline value the mileage rewards and upgrades seat that passenger will get on a specific airline. But what if we added "seat comfort" to that list? Seat comfort is varying from each of airline but certain metrics are objectively measurable, such as seat width and seat pitch, the distance from the back of the seat in front of you to the back of your seat. Even if infrequent airline passenger will not be surprised to know that airline truly estate (particularly in economy class) is shortening [2].

After all, by making the seats narrower and reducing the seat pitch, an airline can obtain number of more paying passengers. It said that "If passenger travel as much as they do, passenger appreciate the development in aircraft characteristic and concept design of lower noise and feel comfort - supply you don't travel in things called economy class, which sounds terrible" [1].

FAA decided it will not regulate the shrinking airline seat as it is not a safety issue and procedure to the airline safety as well as not in the major concern when the airline does not exceed the maximum weight while take off and landing [5].

\footnotetext{
${ }^{*}$ Corresponding author: kangwarn.ph@ssru.ac.th
} 
Radka (2019) recently posted a guide to the US airlines with the widest seats in coach. In regulary cases, the form is slightly limited, but there are some point of fact between winners and losers in their "Best Bets" and "Airlines to Avoid" [11]. Jet Blue, for example, is among the "best bets" with 18 inches of seat width on its Airbus A320 \& A319s. The airline also offers the most legroom in economy class of any U.S. airline in fact of seat pitch (32"-33"). Deeply, the Watchdog select American in the "avoid" group, as the new Boeing 737 MAX and 737-800 provide a "dismal" 30" pitch withing seats in the aircraft that have "diameters as fit as 15.9 and 16.6 inches"[10]. The Watchdog reply, "in general speaking, Airbus can provide passenger that a few of larger leg room around the hips, whereas, the narrow body like Boeing have a tiny seat offering" $[11,12]$.

\section{Theoretical and Analysis}

Over the years, commercial air traffic and the number of passengers has been constantly increasing. The majority reason for this development is the increase of low-cost carriers (LCC). The lower prices of LCCs compared to full-service carriers (FSC) are the reduction of comfort to passenger and some service. FSCs have the abilities to set the comfort to passenger $[6,13]$. The general point of view in factor that influencing comfort and discomfort are including;

1. History of the airline

2. State of mind

3. Visual input

4. Environmental factors (e.g. smell, noise, temperature and humidity)

5. Pressure distribution

6. Posture and Movements

A survey conducted in 1975 mentioned that passengers rated seat comfort as the most important factor influencing discomfort, followed by noise and temperature. Furthermore in year 1999 evaluate study from 930 passengers criticize that their seats concerning the big factors. Legroom (15.7\%), back support (10.2\%) and head support $(9.7 \%)$ were among the five factors rated poor or very poor by the highest percentage of surveyed passengers. On the other hand, it figured out that legroom has a very high influence on aircraft interior comfort $[7,8]$.

The legroom and space are provided for passengers. The airline is focused by seat pitch. In Figure 1 the measures seat pitch (A) and legroom (B) are classified. Seat pitch is defined as the distance from a point on the seat in one row to the same point on a seat in the next row [3]. The depth and the contour of the backrest reduce seat pitch to the available legroom (B). Bauch (2000) defined the measures clearance, width, and, seat pitch, as comfort measures, and stated that maximum comfort is reached at the maximum values of these comfort measures [3,14].

The objectives of this research are;

1. To expressing the factors influencing their well-being and comfort sensations for different seat pitches.

2. To studying the solution way of aircraft seat

The answers led to the following ten expressions which were integrated into the questionnaire of the main study. These statements can be clustered in four categories: 


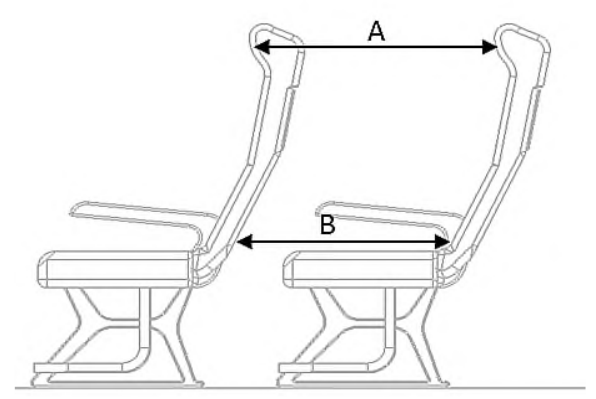

Fig. 1. Seat pitch (A) and legroom (B) (Source: airlinequality.com).

Postural sensation:

I can easily adopt myself a comfortable sitting posture

I can change easily from one sitting style of posture to another posture

Spatial perception:

I feel restricted while seating

I feel restricted by the seat-width

I feel restricted by the length of the armrests

I feel restricted by the length of the seating rows

I feel restricted by my seat-mate

I feel like sitting in front of a brick of wall

Privacy:

I feel unwell because of the length of the seating rows

Present mood:

I feel pressure out because of the length of the seating rows

In addition, the anthropometric measures of each subject are as followed;

stature

sitting height

eye height sitting

acromial height sitting

elbow height sitting

knee height sitting

buttock to knee length

hip width

shoulder width

On the review passengers were advised to sit in their assigned seats and to fasten their seatbelts in the same time that lead to uncomfortable especially during the long-haul flight. They feel guilty and uncomfortable with the short seat pitch even though it is only 1-2 inches different.

Surprisingly, seat pitch really makes a big difference when it comes to your in-flight comfort. It shows a bit less on a short-haul flight, which is passenger seem like to experience a regional jet like Cessna, therefore if passenger are traveling on a transcontinental flight or overseas trip, it is must do the research passenger airline's seating before you pull the stimulation on a cheap flight [4].

Therefore, there are another common seating in the aircraft for passenger that makes passenger can be able to get more comfort during the flight which are including;

1. Airline tries to use sky blue or blue color seat to make passenger will brighter and more comfort. As British scientist said that blue color shows trust and safety. As well as from the research also supports that $90 \%$ of choosing behavior come from color [9]. 
2. Seat leather and seat fabric are well known in every airline. Short flight likely uses leather (PU leather) for the fight especially low-cost carriers. Whereas, fabric seat has been using in long haul flight.

There are several techniques for passenger to choosing the right seat within the limited seat pitch.

1. Trying to look for the best seat form the website before booking is one of the techniques as you can find from seatguru.com [4].

2. If you want the quiet zone, you have to seat at the front wheel area or seat at the aisle seat.

3. Tall person must seat at the emergency

\section{Conclusion and recommendations}

During the long flight time, passenger frustration with decreased seat dimensions has directly faced pressure. Critics of existing seat dimensions have worried that these seats are not only cramped but dangerous. However, the FAA controls airline safety, not the comfort of passengers. Whether the cabin can be evacuated in 90 seconds in case of an emergency is the FAA's metric for determining whether to accept the seating configuration of an aircraft. As long as an airline can prove that it can meet the 90 -second evacuation criteria, there will be no reason for the FAA (under its existing rules and policies) to refuse the seating of an airline.

All the seating that U.S. airlines currently sell has already been licensed by the FAA and the new law would not require the FAA to modify its seat control approach. Meanwhile, the airlines claim that their seat designs are safe and that if the government needs them to raise the seat pitch, they will be forced to increase tariffs and reduce customer choices. As for comfort, the airlines will argue that the marketplace is best equipped to tackle that issue, not the government. By tolerating the smaller, simple economy seating, travelers can choose to pay extra for a more comfortable seat or save some money or just choose to fly on an airline that provides a few more inches.

Industry insiders do not expect the FAA to change its approach to regulating seat dimensions fundamentally, but it will be subject to public consultation when the FAA issues its rule proposal (as mandated by the new legislation). However, for the near future, disgruntled passengers may have no option but to heed the invitation of the airlines to pay more if they want to enjoy a larger seat.

\section{References}

1. K. Balcombe, J.Air. Tran. Mg $\mathrm{t} 2009$

2. A. Bauch, Airbus Conference Center (DGLR, Bonn, 2001)

3. G. Brundet, J. Soci. H (2001)

4. S. Calder, Independent (2016)

5. M. Goldstein, Forbes (2018)

6. K. Kankaew, J. Bus. Sci (2016)

7. D. Lee, J. Air. Tran. Mgt 10, 383 (2004)

8. M. Luengoprado, J. Air. Tran. Mgt 10, 377 (2004)

9. W. Pierce, J. Ash 26, 33 (2004)

10. C. Quigley, Handle (2001)

11. R. Radka, Airfarewatchdog (2019) 
12. M.M. Ihnatenko et al., International J. of Economics and Business Administration 7(2), 290-301 (2019)

13. M.V. Vinichenko et al., Espacios 40(19) (2019)

14. E.V. Andreeva et al., Actual Problems of Economics 183(9), 220-227 (2016) 